\title{
И.Б. Антонов
}

\section{Экспрессия белков ММР при старении миокарда в норме и при дилатационной кардиомиопатии}

Автономная научная некоммерческая организация высшего образования научноисследовательский центр «Санкт-Петербургский институт биорегуляции и геронтологии», просп. Динамо, д. 23, г. Санкт-Петербург, 197110, Российская Федерация Автор для переписки: И.Б. Антонов (ibg@gerontology.ru)

\begin{abstract}
Аннотация
Актуальность: Матриксные металлопротеиназы (ММР), их ингибитор ТIMP, молекулы адгезии, сиртуины и маркеры апоптоза являются одними из сигнальных молекул, имеющих важное значение при прогнозировании развития дилатационной кардиомиопатии. Цель исследования: Изучить экспрессию белков ММР при старении миокарда в норме и при дилатационной кардиомиопатиии. Материалы и методы: Исследование проведено с использованием аутопсийного материала миокарда людей разных возрастных групп с дилатационной кардиопатией и без сердечно-сосудистой патологии. Материал получали в условиях стерильности на базе операционного блока. Образец ткани после отделения сразу опускали в стерильную емкость, содержащую физиологический раствор. Контролем служила культура нормальных кардиомиоцитов человека (линия GirardiHeart), полученная из коллекции клеточных культур Института цитологии РАН (Санкт-Петербург). Для иммуноцитохимического исследования культур и иммуногистохимического анализа аутопсийного материала применяли следующие первичные моноклональные антитела: MMP-2 (Dako, CША) и MMP-9 (Dako, CША). Морфометрическое изучение полученных структур проводили при помощи системы компьютерного анализа микроскопических изображений. Результаты: Установлено, что изменения площади экспрессии ММР-2, ММР-9 в аутопсийном материале миокарда в норме не наблюдалось. При ДК площадь экспрессии ММР-2 увеличивалась в 5,7 раза у пациентов средней возрастной группы, в 6 раз - у людей в пожилом возрасте, в 6,8 раза - у лиц старшего возраста относительно подобного показателя в норме. Содержание ММР-9 в миокарде у пациентов с ДК всех возрастных групп повышалась в 4,5 раза по сравнению с соответствующей возрастной нормой. В культурах нормального миокарда при их старении экспрессия ММР-9 достоверно не изменялась. Заключение: Ключевыми маркерами, характеризующими наличие дилатационной кардиомиопатии у людей разного возраста в аутопсийном и культуральном материале являются матриксные металлопротеиназы.
\end{abstract}

Ключевые слова: экспрессия; старение; миокард; кардиомиопатия

Информация для цитирования: Антонов И.Б. Экспрессия белков ММР при старении миокарда в норме и при дилатационной кардиомиопатии // Научные результаты биомедицинских исследований. 2019. Т. 5, № 1. С. 122-130 [Antonov IB. Expression of MMP proteins in the aging of the myocardium in normal conditions and dilated cardiomyopathy. Research Results in Biomedicine. 2019;5(1):122-130 (In Russian)]. DOI: 10.18413/2313-8955-2019-5-1-0-9 

in normal conditions and dilated cardiomyopathy

\author{
St. Petersburg Institute of Bioregulation and Gerontology, \\ 23 Dinamo Ave., St. Petersburg, 197110, Russia \\ Corresponding author: Igor B. Antonov (ibg@gerontology.ru)
}

\begin{abstract}
Background: Matrix metalloproteinases (MMP), their TIMP inhibitor, adhesion molecules, sirtuins, and apoptosis markers are among the signaling molecules that may have an important prognostic value in dilated cardiomyopathy. The aim of the study: To study the expression of MMP proteins during myocardial aging in normal conditions and in dilated cardiomyopathy. Materials and methods: The work was performed on autopsy material of the myocardium of people of different ages with dilated cardiopathy and without cardiovascular pathology. The material was taken under sterile conditions of the operating unit. Immediately after taking a sample of tissue, it was placed in a sterile container with saline. The control was the culture of normal human cardiomyocytes (line Girardi Heart, obtained from the cell culture collection of the Institute of Cytology RAS (St. Petersburg). For immunocytochemical studies of cultures and immunohistochemical analysis of autopsy material, the following primary monoclonal antibodies were used: MMP-2 (Dako, USA) and MMP-9 (Dako, USA). The morphometric study of the structures obtained was performed using a computer-aided microscopic image analysis system. Results: It was established that the area changes expression of MMP-2, MMP-9 was not normally observed in the myocardial autopsy material. In DC, the area of MMP-2 expression increased 5.7 times in middle-aged people, 6 times in elderly people and 6.8-fold in elderly patients compared with the corresponding indicator in normal conditions. The expression of MMP-9 in the myocardium in patients with DK of all age groups increased by 4.5 times compared with the corresponding age norm. In normal myocardial cultures with their aging, the expression of MMP-9 did not change significantly. Conclusion: Matrix metalloproteinases are the key markers characterizing the presence of dilated cardiomyopathy in people of different ages in the autopsy and cultural material.
\end{abstract}

Keywords: expression; aging; myocardium; cardiomyopathy.

Введение. Патологии сердца и сосудов стоят на лидирующих позициях в списке заболеваний, характеризующихся высокой степенью риска летального исхода [1].

По результатам статистического анализа Всемирной организации здравоохранения (ВО3), 35 и более процентах случаев смертность лиц старших возрастных групп обусловлена патологией сердца и сосудов. Среди заболеваний сердечно-сосудистой системы у пациентов, имеющих возраст более 50 лет, достаточно часто встречается дилатационная кардиомиопатия (ДК) $[2,3$, $4,5]$. Предпосылками ДК являются дилатация сердечных камер, систолическая дис- функция, отмечаемые в большинстве случаев в левом желудочке $[6,7,8]$.

В настоящее время поиск сигнальных молекул для выявления у людей разного возраста ДК имеет важное медикосоциальное значение. Матриксные металлопротеиназы (ММР), их ингибитор ТIMP, молекулы адгезии, сиртуины и маркеры апоптоза рассматриваются как перспективные сигнальные молекулы, изучение которых позволит расширить возможности по диагностике и прогнозированию развития ДК. ММР являются ферментами, обладающими протеолитической функцией. Эти соединения активно участвуют в процессах 
ремоделирования и репарации тканей соединительного типа, составляющей основу сердечно-сосудистой и дыхательной систем $[9,10,11,12,13]$.

Цель исследования - изучить экспрессию белков ММР при старении миокарда в норме и при дилатационнойкардиомиопатиии.

Материалы и методы исследования. Работа проведена на аутопсийном материале, полученном из сердечной мышцы пациентов разных возрастных групп с ДК, а также людей без сердечно-сосудистой патологии. Образцы получали из СПб ГБУЗ «Городская больница святого великомученика Георгия» (С.-Петербург). Все пробы разделяли на группы согласно возрастной классификации ВО3: 1 - люди среднего возраста (45-59 лет), 2 - люди пожилого возраста (60-74 года), 3 - люди старческого возраста (75-89 лет).

Нормальный аутопсийный материал был получен от людей, не имевших сердечно-сосудистой патологии и погибших от других причин.

Ткань миокарда человека для создания культур (диаметр 0,2 см, 4 фрагмента) была забрана от 3-х пациентов мужского пола среднего возраста $(52,3 \pm 2,6)$ с ДК при биопсии сердца, полученных в Клинике сердечно-сосудистой хирургии Военномедицинской академии им. С.М. Кирова (С.-Петербург).

Извлечение образцов ткани осуществляли в стерильных условиях на базе операционного блока. После получения материала клетки сразу опускали в стерильную емкость, содержащую физиологический раствор. Контролем служила культура нормальных кардиомиоцитов человека (линия GirardiHeart, полученная из коллекции клеточных культур Института цитологии РАН (С.-Петербург)). Культуральная среда для кардиомиоцитов состояла из 86,5\% EMEM, $10 \%$ FBS, $1 \%$ NEAA, 1,5\% HEPES, $1 \%$ PES, L-глутамина. Bce культуры выращивали на протяжении 3 пассажей («молодые» клеточные культуры) и 10 пассажей («старые» клеточные культуры). 10 пассаж был выбран в качестве «старых» культур экспериментально, т.к. при последующих пересевах боль- шая часть клеток культуры вступала в апоптоз.

К работе приступили спустя 4 часа после получения образцов миокарда, хранение осуществлялось в холодильнике при $+6^{\circ} \mathrm{C}$.

В стерильных условиях ламинарного шкафа образцы были извлечены из транспортировочной емкости и помещены в чашку Петри, которая имела диаметр 7 см. Образцы обрабатывали сбалансированным раствором Хенкса (HBSS), содержащим соли и антибиотики, такие как пенициллин, стрептомицин (в концентрации 5 мг/мл), в течение 3 раз, чтобы смыть присутствующие изначально кровь и секрет.

С использованием стерильных ножниц материал измельчали до небольших кусочков объемом 1-2 мм³. Образцы помещали в пробирки для центрифугирования, имеющие объем 15 мл, сюда же добавляли 10 мл HBSS, содержащей $0,2 \%$ раствор коллагеназы I (Gibco, активность 205 ед/мг). Около 30 секунд пробы откручивали с использованием вортекса. Далее ткань ставили на инкубацию в термостат при $37^{\circ} \mathrm{C}$ на 20 минут. Образовавшиеся при этом агрегаты клеток диспергировали путем пропускания образцов через пипетку (пипетировали). 8 мл супернатанта с клетками осаждали в течение 5 минут, затем центрифугировали на протяжении 5 минут при 400g. Далее убирали надосадочную жидкость, осадок ресуспедировали в среде M199 (объемом 2 мл), содержащей $10 \%$ эмбриональную бычью сыворотку и антибиотик. Выделение проводили циклически, повторяя процедуру 3 раза. Растворенный осадок помещали в отдельную емкость. Жизнеспособности клеток оценивали с использованием трипанового синего. Краситель добавляли к аликвоте объемом 2 мл, взятой из пробирки с 6 мл накопленных клеток, в равных пропорциях. Считали процентное содержание живых клеток с использованием гемоцитометра (камеры Горяева).

Первичную клеточную культуру выделяли в предварительно обработанных раствором фибриногена (Gibco) чашках Петри (Sarstedt). Далее культивировали материал в обработанных флаконах объемом по 50 мл (Sarstedt $25 \mathrm{~cm}^{2}$ ). Культивирование проводи- 
ли при добавлении во флаконы по мл культуральной среды. В чашки Петри диаметром 3,5 см вливали по 3 мл культуральной среды. При использовании 24-луночного планшета в каждую лунку помещали по 1 мл среды. Стадии монослоя первичная клеточная культура достигала на 5-7 день, в это время ее пересеивали. После наступления состояния монослоя через 3 дня на 4-й сутки осуществляли пассирование. Культивирование клеток проводилось до 3 и 10 пассажа.

С целью иммуноцитохимического исследования культур и иммуногистохимического изучения образцов аутопсийного материала применяли следующие моноклональные антитела первичного типа: ММР-2 (Dako, США) и MMP-9 (Dako, США). Окрашивание препаратов проводилось по стандартному протоколу.

Морфометрическое изучение полученных структур проводили с использованием специального компьютерного комплекса для обработки изображений, полученных с помощью микроскопа. Комплекс включал в себя следующие элементы: микроскоп Olympus BX40, цифровую камеру Olympus, персональный компьютер, базирующийся на IntelPentium 5, программное обеспечение «VideotestMorphology 5.2». В каждой пробе обрабатывали не менее 5 полей зрения при увеличении х200.

Экспрессию для маркеров с цитоплазматическим действием оценивали по площади, равной отношению площади покрытого иммунопозитивными клетками участка к общей площади клеток, расположенных в поле зрения. Для маркеров с ядерным выражением площадь экспрессии рассчитывали как отношение площади участка, содержащего иммунопозитивные ядра, к общей площади ядер, встречающихся в поле зрения. Площадь экспрессии измеряли в процентном отношении.

Полученные результаты обрабатывали методами вариационной статистики использованием программы Statistica 11.0.
Вычисляли по каждой выборке среднее арифметическое, стандартное отклонение, доверительный интервал. Для каждой выборки доказано нормальное распределение значений. Статистическую однородность разных выборок проверяли с помощью критерия Крускала-Уоллиса (непараметрического однофакторного дисперсионного анализа). По критерию Стьюдента критический уровень достоверности нулевой гипотезы об отсутствии различий считали равным 0,01 .

Результаты исследования и их обсуждение. В результате эксперимента было установлено, что площадь экспрессии молекул ММР-2 в аутопсийных образцах сердечной мышцы у пациентов средней, пожилой и старческой возрастной группы составила $0,74 \pm 0,18 \%, 0,82 \pm 0,22 \%$ и $0,80 \pm 0,20 \%$ соответственно, достоверных отличий не выявлено. При развитии ДК выраженность данного маркера значительно повысилась в 5,7 раз у лиц средней возрастной группы, в 6 раз - у пожилых пациентов, в 6,8 раз - у пациентов старческого возраста. При ДК площадь экспрессии ММР-2 не зависела от возраста (рис. 1).

Экспрессия ММР-2 в «молодой» культуре миокарда в норме составила $0,40 \pm 0,06 \%$. В «старой» культуре миокарда в норме этот показатель уменьшился в 1,5 раза и был равен $0,27 \pm 0,04 \%$. При оценке экспрессии сигнальной молекулы ММР-2 при развитии ДК установили, что показатель ее площадь возрос в 5,4 раза в «молодых» клеточных культурах $(2,17 \pm 0,11 \%)$, в 8,9 раз - в «старых» клеточных культурах $(2,39 \pm 0,14 \%)$ по сравнению с нормой (рис. 2).

Площадь экспрессии ММР-9 в аутопсийном материале миокарда в норме у людей среднего, пожилого и старческого возраста составила соответственно $1,76 \pm 0,24 \%$, $1,80 \pm 0,20 \%$ и $1,85 \pm 0,27 \%$ и достоверно не различалась (рис. 3). 


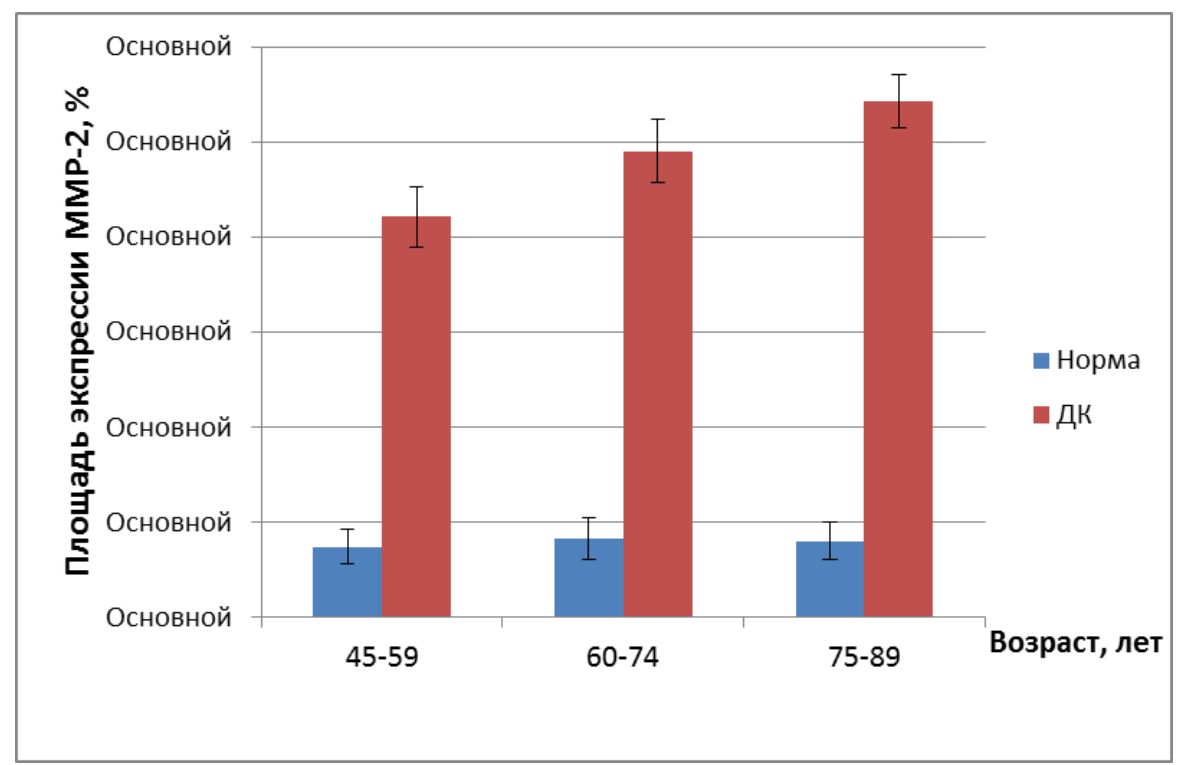

Рис. 1. Экспрессии ММР-2 в аутопсийном материале миокарда в норме

и при дилатационной кардиомиопатии

* - p $<0,05$ по сравнению с соответствующим показателем в группе 45-59 лет;

** - $<<0,05$ по сравнению с соответствующим показателем в норме.

Fig. 1. Expression of MMP-2 in the autopsy myocardial material in normal conditions and in dilated cardiomyopathy

$*-p<0.05$ compared with the corresponding indicator in the group of 45-59 years;

$* *-\mathrm{p}<0.05$ compared with the corresponding indicator in the norm.

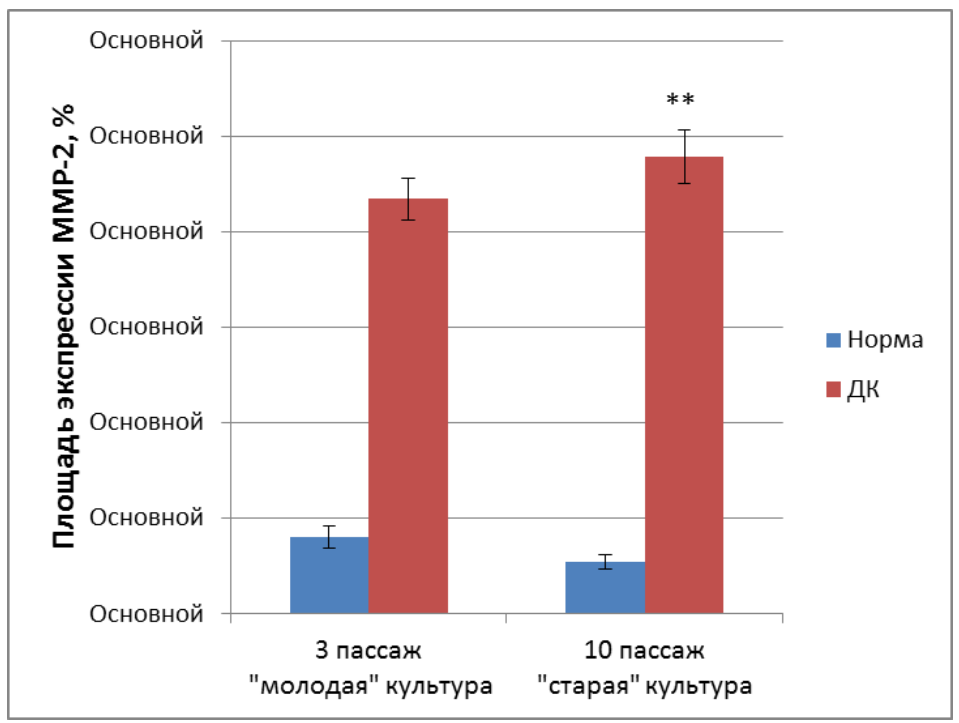

Рис. 2. Экспрессия ММР-2 в культуре миокарда в норме и при дилатационной кардиомиопатии * - $<0,05$ по сравнению с соответствующим показателем в «молодой» культуре;

** - $\mathrm{p}<0,05$ по сравнению с соответствующим показателем в норме.

Fig. 2. Expression of MMP-2 in the myocardial culture in normal conditions and in dilated cardiomyopathy

$*-p<0.05$ compared with the corresponding indicator in the "young" culture;

$* *-p<0.05$ compared with the corresponding indicator in the norm. 


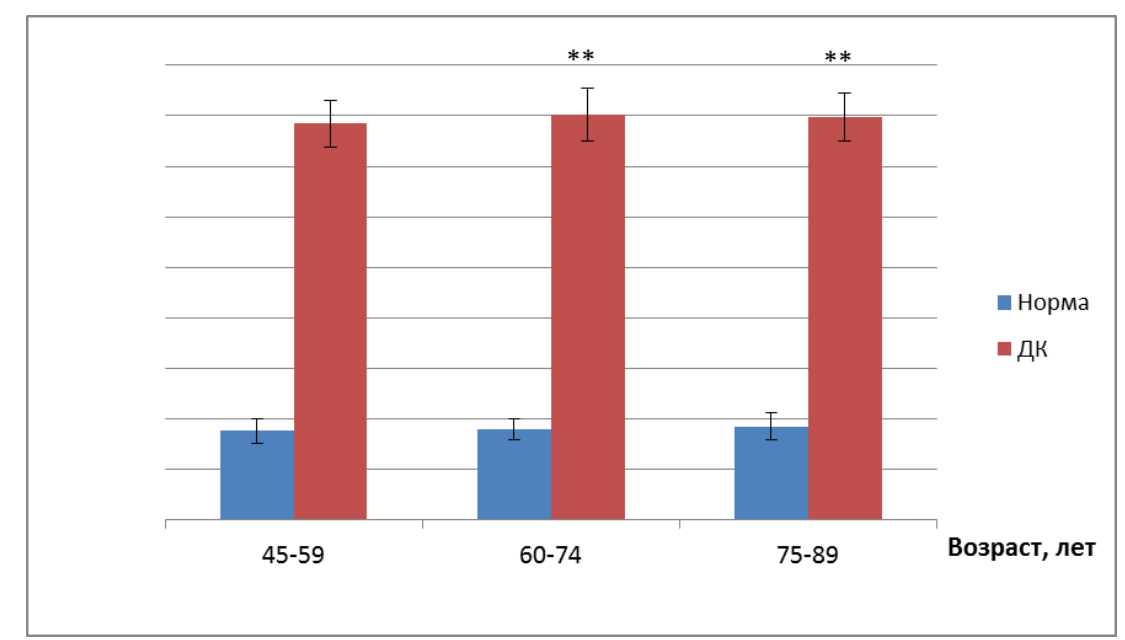

Рис. 3. Экспрессии ММР-9 в аутопсийном материале миокарда в норме и при дилатационной кардиомиопатии

** - $<<0,05$ по сравнению с соответствующим показателем в норме.

Fig. 3. Expression of MMP-9 in the autopsy myocardial material in normal conditions and in dilated cardiomyopathy

$* *-p<0.05$ compared with the corresponding indicator in the norm.

Выявлено увеличение в 4,5 раза экспрессии молекул ММР-9 при развитии ДК у пациентов всех возрастов. С возрастом площадь выражения молекул ММР-9 при ДК достоверно не изменялась.

Площадь экспрессии ММР-9 в «молодой» культуре миокарда в норме составила $0,69 \pm 0,13 \%$. В «старой» культуре экспрес- сия этой сигнальной молекулы достоверно не изменилась и была равна $0,74 \pm 0,10 \%$. Экспрессия ММР-9 в культурах, полученных от пациентов с ДК, увеличилась в «молодых» культурах в 5,7 раза по сравнению с соответствующей нормой и составила $3,94 \pm 0,22 \%$, а в «старых» культурах - в 6 раз до $4,50 \pm 0,18 \%$ (рис. 4 ).

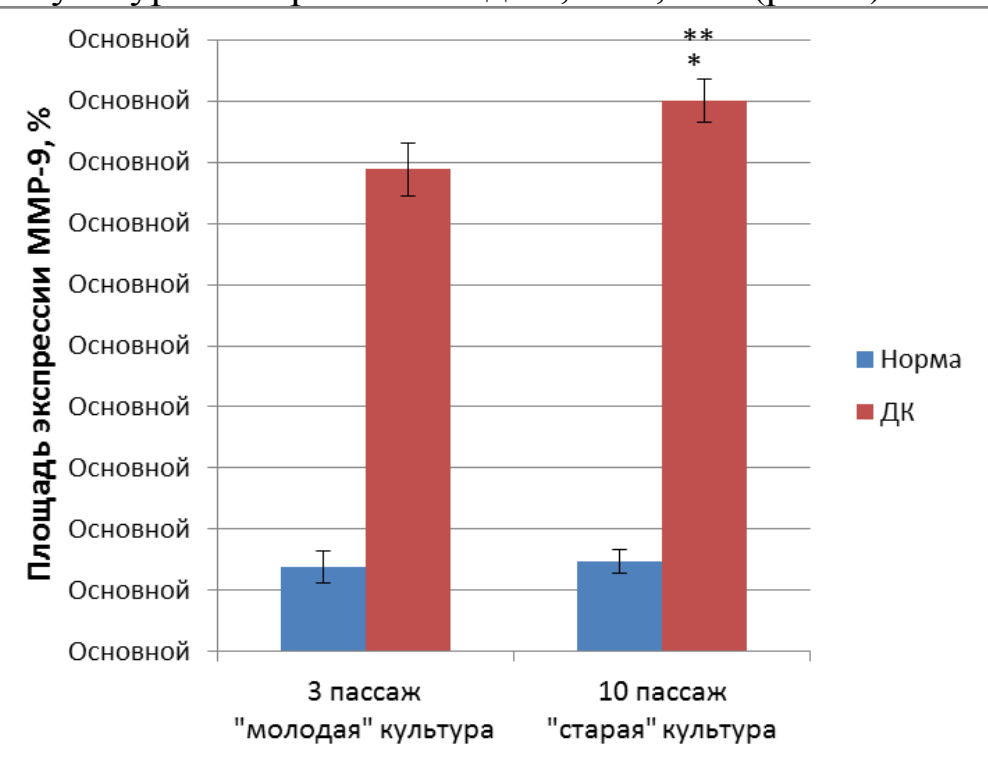

Рис. 4. Экспрессия ММР-9 в культуре миокарда в норме и при дилатационной кардиомиопатии * - p<0,05 по сравнению с соответствующим показателем в "молодой" культуре; ** - $<<0,05$ по сравнению с соответствующим показателем в норме.

Fig. 4. Expression of MMP-9 in the myocardial culture in normal conditions and in dilated cardiomyopathy

$*-p<0.05$ compared with the corresponding indicator in the "young" culture; $* *-p<0.05$ compared with the corresponding indicator in the norm. 
Изменение площади экспрессии ММР9 в аутопсийном материале миокарда и в культуре миокарда имеет схожую тенденцию в норме и при ДК.

Установлено, что изменения площади экспрессии ММР-2, ММР-9 в аутопсийном материале миокарда в норме не наблюдалось. При ДК площадь экспрессии ММР-2 увеличивалась в 5,7 раза у людей средней возрастной группы, в 6 раз - у пожилых пациентов, в 6,8 раза - у людей старческой|го возрастного периода относительно соответствующего показателя в норме. Кроме того, наблюдалось увеличение экспрессии маркера ММР-2 в 1,5 раза при старении культуры кардиомиоцитов в норме. При этом в кардиомиоцитах, полученных от пациентов с ДК, в «молодых» культурах экспрессия ММР-2 повышалась в 5,4 раза, а в «старых» культурах - в 8,9 раза по сравнению с нормой. Полученные нами данные хорошо согласуются с результатами, описанными другими исследователями. Известно, что при ДК происходит повышение синтеза ММР-2 $[14,15]$.

Экспрессия ММР-9 в миокарде у пациентов с ДК всех возрастных групп повышалась в 4,5 раза по сравнению с соответствующей возрастной нормой. В культурах нормального миокарда при их старении экспрессия ММР-9 достоверно не изменялась. В культурах миокарда, полученного от пациентов с ДК, экспрессия ММР-9 повышалась в 5,7 и 6 раз соответственно для «молодых» и «старых» культур. В предыдущих исследования по данным литературы было обнаружено, что отмечалась повышенная экспрессия ММР-9 при наличии сердечнососудистых патологий, в том числе при развитии ДК, что соответствует полученными нами результатам [14, 16, 17]. Предполагается, что усиление экспрессии молекул ММР-2 и ММР-9 обусловлено тем, что данные металлопротеиназы относятся к полифункциональным протеинам и играют важную роль в таких процессах, как ангиогенез и апоптоз, которые патологически изменяются при развитии ДК $[18,19,20]$.

Заключение. Ключевыми маркерами, характеризующими наличие дилатационнойкардиомиопатииу людей разного возраста в аутопсийном и культуральномматериале являются матриксные металлопротеиназы.

В отношении данной статьи не было зарегистрировано конфликта интересов.

\section{Список литературы}

1. Сравнительная характеристика профилактики сердечно-сосудистых заболеваний в Украине и Европе по данным euroaspire IV: госпитальная линия / В.Н. Коваленко [и др.] // Артериальная гипертензия. 2016. N 1(45). С. 29-34.

2. Жиров И.В., Осмоловская Ю.Ф., Терещенко С.Н. По следам последних клинических рекомендаций. Антагонисты минералокортикоидных рецепторов // Медицинский совет. 2015. N 4. C. 46-51.

3. Modernized classification of cardiac antiarrhythmic drugs / M. [et al.] // Circulation. 2018. Vol. 138(17). P. 1879-1896. DOI: https://doi.org/10.1161/CIRCULATIONAHA.118.0 35455

4. McKenney J.R. Clinical lipidology: a companion to Braunwald's Heart Disease // Statins. 2015. N 1. P. 227-256. DOI: https://doi.org/10.1016/B978-141605469-6.50026-3

5. Rader D.J. Human genetics of atherothrombotic disease and its risk factors // Arterioscler. Thromb. Vasc. Biol. 2015. Vol. 35(4). P. 741-747.

DOI: https://doi.org/10.1161/ATVBAHA.115.305492

6. Башкирева А.С., Артамонова В.Г. Пептидергическая коррекция невротических состояний у водителей грузового автотранспорта // Успехи геронтологии. 2012. Т. 25, N 4. С. 718-728.

7. Зотова Л.А. Дилатационная кардиомиопатия: современный взгляд на заболевание // Российский медико-биологический вестник имени академика И.П. Павлова. 2013. N 1. C. 151-157.

8. Van Grootel R.W., Strachinaru M., Menting M.E. In-depth echocardiographic analysis of left atrial function in healthy adults using speckle tracking echocardiography and volumetric analysis // Echocardiography. 2018. Vol. 10(1). P. 14-17. DOI: https://doi.org/10.1111/echo.14174

9. Анализ дифференциальной экспрессии матриксных металлопротеиназ в стабильной и нестабильной атеросклеротических бляшках методом полногеномного секвенирования РНК: пилотное исследование / Д.Е. Иванощук [и др.] // Российский кардиологический журнал. 2018. N 23(8). C. 52-58.

10. Козлов К.Л., Солдатов В.М., Полякова В.О. Молекулярные аспекты старения сосу- 
дов in vitro // Молекулярная медицина. 2015. N 3. C. 53-56.

11. Хавинсон В.Х., Линькова Н.С., Елашкина Е.В. Молекулярные аспекты антиатеросклеротического действия коротких пептидов // Клеточные технологии в биологии и медицине. 2014. N 3. C. $185-189$.

12. Defourny J., Thelen N., Thiry M. Cochlear connexin 30 homomeric and heteromeric channels exhibit distinct assembly mechanisms // Mech Dev. 2018. N 5. P. 25-37. DOI: https://doi.org/10.1016/j.mod.2018.10.001

13. Kraskovskaya N.A., Kukanova E.O., Linkova N.S. Tripeptides restore the number of neuronal spines under conditions of in vitro modeled alzheimer's disease // Bull Exp Biol Med. 2017. Vol. 163(4). P. 550-553. DOI: https://doi.org/10.1007/s10517-017-3882-z

14. Bornstein P. Matricellular proteins: an overview // J. Cell Commun Signal. 2009. Vol. 3(3-4). P.163-165. DOI: https://doi.org/10.1007/s12079-009-0069-z

15. Пальцев М.А., Солдатов В.М, Козлов К.Л. Экспрессия сигнальных молекул в эндотелии аорты при старении и атеросклерозе // Молекулярная медицина. 2015. N 5. С. 12-15.

16. Эффективность пептидного биорегулятора сосудов в комплексной терапии васкулогенной эректильной дисфункции у лиц старших возрастных групп / К.В. Китачев [и др.] // Успехи геронтологии. 2014. Т. 27, N 1. С. 156-159.

17. Laird D.W., Lampe P.D. Therapeutic strategies targeting connexins. Nat Rev Drug Discov. 2018. N 12. P. 10-20. DOI: https://doi.org/10.1038/nrd.2018.138

18. Китачев К.В., Сазонов А.Б., Козлов К.Л. Роль вазоактивного пептида в лечении хронической артериальной недостаточности нижних конечностей // Успехи геронтологии. 2013. T. 26, N 2. C. 292-296.

19. Солдатов В.М., Козлов К.Л., Линькова Н.С. Возрастные особенности экспрессии сигнальных молекул в эндотелии сосудов человека и их роль в развитии сердечно-сосудистой патологии // Молекулярная медицина. 2015. N 6. C. 33-37.

20. Pitha J., Kralova L.I., Hubacek J.A. Smoking impairs and circulating stem cells favour the protective effect of the $\mathrm{T}$ allele of the connexin 37 gene in ischemic heart disease // Atherosclerosis. 2016. N $244 . \quad$ P. 73-78. DOI: https://doi.org/10.1016/j.atherosclerosis.2015.11.007

\section{References}

1. Kovalenko VN, Dolzhenko MN, Nesukay EG, et al. [Comparative characteristics of the prevention of cardiovascular diseases in Ukraine and Europe according to euroaspire IV: hospital line]. Arterialnaya gipertenziya. 2016;1(45):29-34. Russian.

2. Zhirov IV, Osmolovskaya YuF, Tereschenko SN. [In the wake of the latest clinical recommendations. Mineralocorticoid receptor antagonists]. Meditsinskiy sovet. 2015;4:46-51. Russian.

3. Lei M, Wu L, Terrar DA, et al. Modernized classification of cardiac antiarrhythmic drugs. Circulation. 2018;138(17):1879-1896. DOI: https://doi.org/10.1161/CIRCULATIONAHA.118.0 35455

4. McKenney JR. Clinical lipidology: a companion to Braunwald's Heart Disease. Statins. 2015;1:227-256.

DOI: https://doi.org/10.1016/B978-141605469-6.50026-3

5. Rader DJ. Human genetics of atherothrombotic disease and its risk factors. Arterioscler. Thromb. Vasc. Biol. 2015;35(4):741-747. DOI: https://doi.org/10.1161/ATVBAHA.115.305492

6. Bashkireva AS, Artamonova VG. [Peptidergic correction of neurotic conditions in truck drivers]. Achievements of gerontology. 2012;25(4):718-728. Russian.

7. Zotova LA. [Dilated cardiomyopathy: a modern view of the disease]. Rossiyskiy medikobiologicheskiy vestnik imeni akademika I.P. Pavlova. 2013;1:151-157. Russian.

8. Van Grootel RW, Strachinaru M, Menting ME. In-depth echocardiographic analysis of left atrial function in healthy adults using speckle tracking echocardiography and volumetric analysis. Echocardiography. 2018;10(1):14-17. DOI: https://doi.org/10.1111/echo.14174

9. Ivanoschuk DE, Ragino YuI, Shahtshneyder EV, et al. [Analysis of differential expression of matrix metalloproteinases in stable and unstable atherosclerotic plaques by the method of genome-wide RNA sequencing: a pilot study]. Rossiyskiy kardiologicheskiy zhurnal. 2018;23(8):52-58. Russian.

10. Kozlov KL, Soldatov VM, Poliakova VO. [Molecular aspects of vascular aging in vitro]. Molecular medicine. 2015;3:53-56. Russian.

11. Havinson VH, Linkova NS, Elashkina $\mathrm{EV}$. [Molecular aspects of the anti-atherosclerotic action of short peptides]. Cell technology in biology and medicine. 2014;3:185-189. Russian.

12. Defourny J, Thelen N, Thiry M. Cochlear connexin 30 homomeric and heteromeric channels exhibit distinct assembly mechanisms. Mech 
Dev.

2018;5:25-37.

DOI:

https://doi.org/10.1016/j.mod.2018.10.001

13. Kraskovskaya NA, Kukanova EO, Linkova NS. Tripeptides restore the number of neuronal spines under conditions of in vitro modeled alzheimer's disea. Bull Exp Biol Med. 2017;163(4):550-553.

DOI: https://doi.org/10.1007/s10517-017-3882-z

14. Bornstein P. Matricellular proteins: an overview. J. Cell Commun Signal. 2009;3(34):163-165. DOI: https://doi.org/10.1007/s12079009-0069-z

15. Paltsev MA, Soldatov VM, Kozlov KL. [Expression of signaling molecules in aortic endothelium during aging and atherosclerosis]. Molecular medicine. 2015;5:12-15. Russian.

16. Kitachev KV, Sazonov AB, Kozlov KL, et al. [Efficacy of a peptide bioregulator of blood vessels in the complex therapy of vasculogenic erectile dysfunction in older age groups]. Achievements of gerontology. 201427(1):156-159. Russian.

17. Laird DW, Lampe PD. Therapeutic strategies targeting connexins. Nat Rev Drug Discov. 2018;12:10-20. DOI: https://doi.org/10.1038/nrd.2018.138

18. Kitachev KV, Sazonov AB, Kozlov KL. [The role of the vasoactive peptide in the treatment of chronic arterial insufficiency of the lower extremities]. Achievements of gerontology. 2013;26(2):292-296. Russian.

19. Soldatov VM, Kozlov KL, Linkova NS. [Age-related features of the expression of signaling molecules in human vascular endothelium and their role in the development of cardiovascular pathology]. Molecular medicine. 2015;6:33-37. Russian.
20. Pitha J, Kralova LI, Hubacek JA. Smoking impairs and circulating stem cells favour the protective effect of the $\mathrm{T}$ allele of the connexin 37 gene in ischemic heart disease. Atherosclerosis. 2016;244:73-78.

DOI: https://doi.org/10.1016/j.atherosclerosis.2015.11.00 7

\section{Информация об авторе}

Игорь Борисович Антонов, научный сотрудник лаборатории возрастной патологии сердечно-сосудистой системы отдела клинической геронтологии и гериатрии, АННО ВО НИЦ «Санкт-Петербургский институт биорегуляции и геронтологии», E-mail: ibg@gerontology.ru.

\section{Information about the author}

Igor B. Antonov, Researcher of the Laboratory of Age Pathology of the Cardiovascular System of the Department of Clinical Gerontology and Geriatrics, St. Petersburg Institute of Bioregulation and Gerontology, E-mail: ibg@gerontology.ru.

Статья поступила в редакцию 9 сентября 2018 г. Receipt date 2018 September 9.

Статья принята к публикации 11 декабря 2018 г. Accepted for publication 2018 December 11. 